\title{
The Function of Remote Sensing in Support of Environmental Policy
}

\author{
Jan de Leeuw ${ }^{1,2}$, , Yola Georgiadou ${ }^{2}$, Norman Kerle ${ }^{2}$, Alfred de Gier ${ }^{2}$, Yoshio Inoue ${ }^{3}$, \\ Jelle Ferwerda $^{2}$, Maarten Smies ${ }^{4}$ and Davaa Narantuya ${ }^{5}$ \\ 1 International Livestock Research Institute (ILRI), Nairobi, Kenya \\ 2 ITC, University of Twente, Enschede, The Netherlands; E-Mails: georgiadou@itc.nl (Y.G.); \\ kerle@itc.nl (N.K.); degier@itc.nl (A.G.); j.g.ferwerda@utwente.nl (J.F.) \\ 3 NIAES, Ecosystem Research Group, Tsukuba, Japan; E-Mail: yinoue@affrc.go.jp \\ 4 Frogs International Environmental Management and Consultancy, The Hague, The Netherlands; E- \\ Mail: maarten@smies.org \\ 5 Ministry of Environment, Ulan Bataar, Mongolia; E-Mail: dnarantuya@yahoo.co.uk \\ * Author to whom correspondence should be addressed; E-Mail: j.leeuw @ cgiar.org; \\ Tel.: +254-20-422-4831.
}

Received: 20 May 2010; in revised form: 13 June 2010 / Accepted: 17 June 2010 /

Published: 12 July 2010

\begin{abstract}
Limited awareness of environmental remote sensing's potential ability to support environmental policy development constrains the technology's utilization. This paper reviews the potential of earth observation from the perspective of environmental policy. A literature review of "remote sensing and policy" revealed that while the number of publications in this field increased almost twice as rapidly as that of remote sensing literature as a whole ( 15.3 versus $8.8 \% \mathrm{yr}^{-1}$ ), there is apparently little academic interest in the societal contribution of environmental remote sensing. This is because none of the more than 300 peer reviewed papers described actual policy support. This paper describes and discusses the potential, actual support, and limitations of earth observation with respect to supporting the various stages of environmental policy development. Examples are given of the use of remote sensing in problem identification and policy formulation, policy implementation, and policy control and evaluation. While initially, remote sensing contributed primarily to the identification of environmental problems and policy implementation, more recently, interest expanded to applications in policy control and evaluation. The paper concludes that the potential of earth observation to control and
\end{abstract}


evaluate, and thus assess the efficiency and effectiveness of policy, offers the possibility of strengthening governance.

Keywords: earth observation; remote sensing; environment; policy; governance

\section{Introduction}

Remotely sensed earth observation (EO) has revolutionized our understanding of our dynamic environment. The array of remotely sensed EO techniques expanded in the 1970s when digital satellite borne imagery complemented aerial photography, which had been available since the early 20th century. Today, the number of EO systems designed to observe and monitor environmental processes is large and continues to grow. Government support for this is strong, as many environmental remote sensing systems are publicly funded, and an increasing number of countries invest in EO infrastructure.

Environmental concern is a major driver for the public support to earth observation. The reverse is true as well; EO stimulates environmental awareness and concern. In An Inconvenient Truth, Gore [1] describes how a single image of the earth, taken in December 1968 by a crew member of the Apollo 8 mission, "exploded into the consciousness of mankind. In fact, within two years of this picture being taken, the modern environmental movement was born. The Clean Air Act, the Clean Water Act, the Natural Environmental Policy Act, and the first Earth Day all came about within a few years of this picture being seen for the first time".

Satellite borne remote sensing and modern environmental policy thus came of age at the same time. The launch of the first Landsat satellite in the early 1970s coincided with the development of the first environmental policies, and the subsequently established environmental protection agencies created the initial demand for environmental EO products.

Following an increase of Landsat applications in the 1970s, in the early 1980s, the question was raised whether the market could recover the costs of earth observation. The Landsat program, which was commercialized in 1982 (a decision reversed in 1992 for military reasons) resulted in a fall back of the utilization of and the non military societal benefits obtained from remote sensing [2]. Since then, the debate has continued between proponents of commercialization and those arguing that the societal benefits of environmental EO merit continuing public support.

Commercialization of environmental EO assumes that viable markets exist. The demand for environmental EO, however, depends considerably on policy and market opportunities, and should thus be considered in the context of societal demand and the policies the EO serves. The countries represented in the Group on Earth Observation (GEO) recognized this dependency on societal demand, while agreeing in February 2005 to develop a Global Earth Observation System of Systems (GEOSS). This initiative aims to develop the societal benefits of EO in nine specific benefit areas $[3,4]$.

A systematic insight in, and awareness of, how remote sensing may contribute to environmental policy can help to enlarge the societal demand for EO applications. However, existing reviews of environmental EO applications are structured according to products, techniques, or benefit areas, rather than the function they have, with respect to the policy they support. In this paper, we review the 
potential, actual contribution, and limitations of EO from the perspective of their support for environmental policy.

\section{Environmental Policy}

Good governance requires effective and efficient policies. Policies, in turn, require information to assess the need and urgency to develop policy, to mobilize instruments for implementation, to control and enforce proper execution, and to monitor and evaluate policy effects. Lack of information, which previously may have hampered the efficiency and effectiveness of policies, is rapidly overcome, while emerging information techniques change the practice of environmental policy [5]. Hence, given this changing technical arena and our ambition to better understand the relation between EO and policy, it would be interesting to consider the contribution of remote sensing from a functional perspective; in other words, how does remote sensing contribute towards enhancing the effectiveness and efficiency of environmental policies?

Several policy models have sought to unravel the policy making process in a number of phases [6]. In this paper, we use the policy cycle to review the potential and actual use of remote sensing in support of environmental policy.

Several policy scientists have criticized the policy cycle approach. They point out that policy is rarely the product of an orderly sequence of stages (or steps in the cycle), where a problem is defined, alternative solutions are analyzed, the best solution is selected and implemented by the executive branch, and later evaluated and revised accordingly, as if on conveyor belt [7]. Sabatier's [8] assessment of the policy cycle heuristic consists of several criticisms, including the lack of causal drivers that govern the policy process within and across stages, the top-down legalistic bias, and the bracketing-out of multiple levels of government involved. However, the popularity of the policy cycle metaphor continues unabated because it allows us to analyze the complexities of the real world [9]. For the purposes of this research, the policy cycle is particularly useful because it helps the matching of information needs and gaps with stages in the policy cycle. Thus, the cycle helps with the alignment of remote sensing information technology with the policies underlying environmental management.

Following Esty [5], we divide the policy process into a series of stages-in this case, problem identification and the formulation, implementation, control, and evaluation of policy (Figure 1). We use this structure to review the function of EO in supporting these various parts of the policy cycle, while surveying not only the potential and current use of remote sensing, data gaps, and knowledge deficiencies, but also governance questions. 
Figure 1. Scheme of a policy cycle.

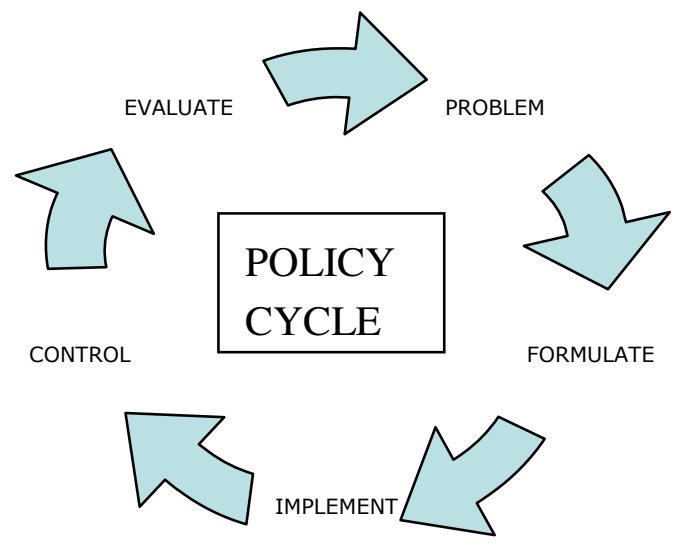

\section{Problem Identification}

Revenga [10] argues that EO has the potential to assess the necessity of developing policy. There are however, few publicly available documented cases describing how remote sensing influenced actual policy development. The detection of the ozone hole is probably the best documented example of EO triggering policy development [11]. Concern about the detrimental effect of chlorofluorocarbons (CFCs) on the ozone layer [12] stimulated the US Congress to commission NASA to develop a sensor (TOMS) to monitor the state of the ozone layer. The sensor, launched in 1978 on-board the NIMBUS satellite, did not report any anomalies until 1986, when NASA confirmed (Figure 2) that the deepening and enlargement of the size of the ozone hole had indeed occurred since the late 1970s [13]. This confirmation, based on re-analysis of the TOMS data, responded to a paper one year earlier, which woke up the world by reporting a steady decline of spring ozone concentrations over one British Antarctic Survey research station [14]. In response to these findings, the 1987 Montreal Protocol [15] prescribed a 50\% reduction, and four years later, a complete ban on the use of hard CFCs.

Figure 2. Size and depth (Dobson units) of the ozone hole in October of 1979, 1982, and 1985, as detected by TOMS [16].
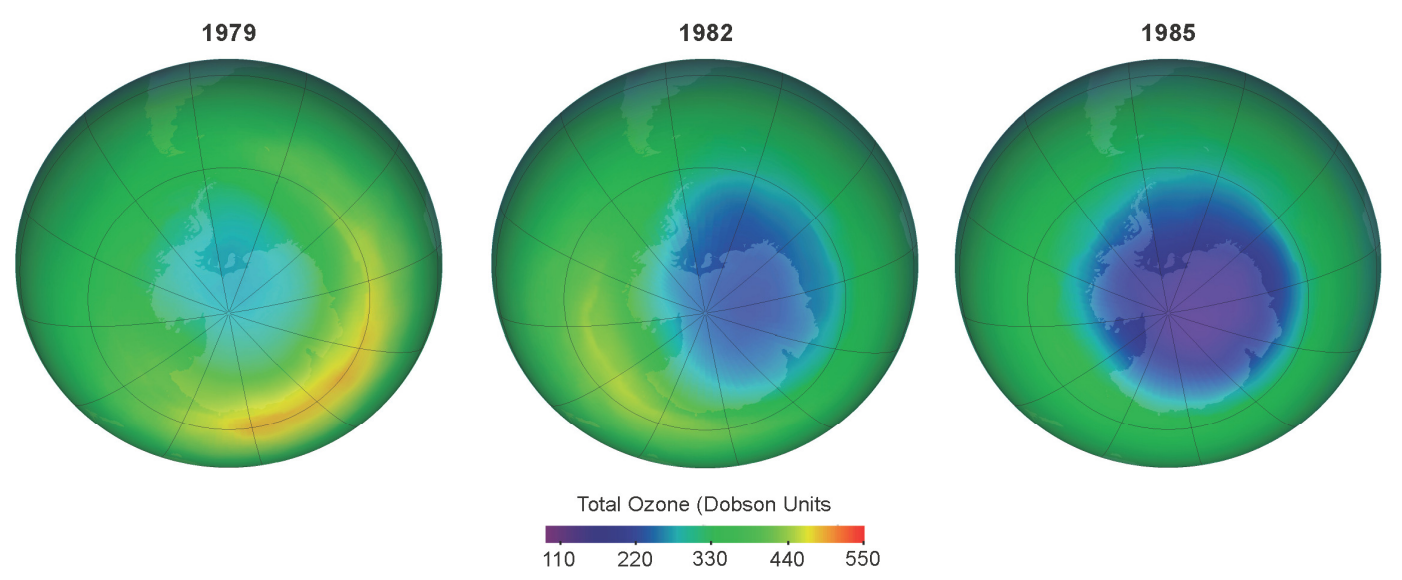
What was new in the remote sensing data? After all, the British Antarctic Survey reported earlier a reduction in spring ozone concentration over their Antarctic research station. The remote sensing confirmed that this record from a single station was not an anomaly, and revealed the size and depth of the hole more convincingly than an entire array of ground based sensors could.

Recognition of environmental problems is frequently confirmed, but rarely initiated by earth observation; other sources of information generally precede quantification by earth observation. For example, the recent remotely sensed detection of increased water turbidity due to dredging (Figure 3) in Northern Poyang Lake, China [17], which was followed by a ban on sand mining, was preceded by reports expressing concern about the impacts of dredging [18,19]. The findings of Wu et al. [17], however, which quantified the extent of the problem, and which had been communicated to provincial government officials half a year before the ban, probably placed the issue higher on the political agenda.

Figure 3. Water turbidity (blue = clear, white $=$ turbid) and distribution of vessels (red dots) in Northern Poyang Lake, China (Courtesy Wu Guofeng).

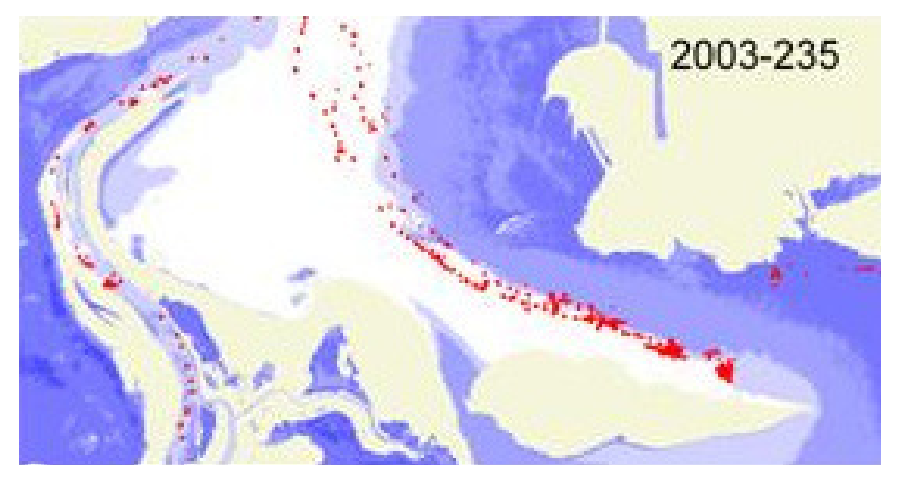

Apart from these examples, few other sources attribute the formulation of environmental policy to remote sensing. Presumably, this is because the diffuse nature of the process leading to policy formulation makes it difficult to assess the precise contribution of EO. Remote sensing contributes, however, increasingly to high level influential policy studies. One example is the FAO's global Forest Resource Assessments [20], which, while based on reports from national forest surveys, have a separate remote sensing survey since the 1990s, as a complement to the main assessment report. Other examples of policy relevant information from EO include the recent assessments of the rate of polar sea ice cover reduction [21] and the melting of the Arctic [22] and Antarctic ice caps and the Third and Fourth Assessment Reports of the Intergovernmental Panel on Climate Change [23,24]. Through these channels, remote sensing contributed without doubt to the development of policies on climate change adaptation and mitigation, deforestation, and trade in forest products.

It will be clear that earth observation infrastructure and products, such as satellites, imaging devices, and imagery, are required to enable the support of international policies, and there have been various initiatives to assess the needs and existing capacity. For example, the second report on the adequacy of the global observing systems for climate in support of the UNFCCC [25], which identified that climate observation systems were not adequate, led to a stronger commitment of governments to address these inadequacies and to produce a true global climate observing infrastructure. 
The function of remote sensing in this phase can thus be resumed as providing information for scrutinizing the necessity to address environmental problems. As indicated above, remote sensing does not champion in initiating problem recognition. Remote sensing has however, unrivalled potential in verifying objectively whether problems exist, and to assess their extent and magnitude synoptically across a range of scales. Additionally, with the gradual construction of the remotely sensed archive, remote sensing can make assessments over longer time periods than most other data collection techniques could.

\section{Policy Implementation}

Current environmental policy literature distinguishes between traditional regulatory instruments, where the nation state or a union of states (e.g., European Union) specifies the goal to be achieved and how, and new environmental policy instruments (so-called NEPIs), which delegate substantial regulatory power to non-state actors [26]. Here we consider traditional regulatory policy instruments including, for example, (i) legislation specifying the liability for environmental damage, (ii) spatial planning, (iii) environmental impact assessment, (iv) financial instruments, and (v) disaster risk management, all of which are specified by state actors or unions of states. How can these policy instruments be supported by remote sensing, and what are the strengths and limitations of this support?

\subsection{Legislation}

The implementation of environmental legislation creates demand for EO. The ESA website of successful EO products [27] describes, for example, how a remote sensing company supplies radar based measurement of subsidence to assist an oil company to decide how much water to inject to counter the downward movement. At first, this might be perceived as a case where the demand for EO emerges from the private market in the form of an oil company contracting the EO industry. The demand for EO, however, emerges because legislation stimulates oil companies to avoid subsidence related damage claims.

Environmental legislation and liability for damage stimulate demand for EO also as a result of development of corporate environmental policy. The introduction of ISO 14001 in 1996 facilitated the implementation of environmental management in company operations. This ISO standard allows companies to certify that they conform, and ensure compliance with environmental laws and regulations. Remote sensing could support implementation of the ISO standards, for example, as follows. Most countries use "normal oilfield practice" as a condition for (exploration and) production concessions, which implies that the concession holder returns the concession in its original condition (i.e., before oilfield development started) once production ceases. In the 1990s, Shell used remote sensing to establish the baseline situation for oil and gas development projects in Russia. Historic RS data may be used to establish an environmental baseline retrospectively, in cases where oilfields are being abandoned without an available environmental baseline that is reliable. Remote sensing continues to be underused in establishing environmental baselines and in supporting corporate environmental policy. 


\subsection{Spatial Planning}

While GIS is the primary analytical platform for spatial planning, remote sensing plays an important subsidiary role. Remote sensing (including aerial photography) can supply baseline information for land-use and other forms of spatial planning in areas where maps are not available, such as in developing countries [28]. Remote sensing also fills a gap in areas with a mapping record by providing the data to update maps, because planning starts with a review of the current situation, which cannot be assessed from outdated maps. The legal implications of the accuracy of the information used in planning might further require currency of information. Comparison with historic remote sensing imagery is frequently used to analyze environmental change to understand those trends requiring consideration from a policy perspective. Finally, remote sensing is used as an input for the modelling of alternative land use options (e.g., agriculture or biological conservation). Hence, remote sensing contributes to the improvement of spatial planning in a variety of ways.

\subsection{Environmental Impact Assessment}

Environmental impact assessment (EIA) is "the process of identifying, predicting, evaluating, and mitigating biophysical, social, and other effects of development proposals prior to major decisions being taken and commitments made" [29]. Nowadays, EIA is compulsory and is included in the environmental legislation of most countries. Increasingly, environmental impacts are considered in their spatial context, while visually assessing the spatial implications and expected impacts of a number of alternative scenarios [30]. EIA in general, and spatially explicit EIA in particular, require reliable and up to date spatial information, because EIAs consider specific and localized development activities, such as the construction of roads or the opening of mines, the impact of which varies spatially. Remote sensing contributes to this, while it allows the updating of the baseline spatial information, such as vegetation and land use, to the current status [31].

\subsection{Financial Instruments}

Financial policy instruments include subsidies, taxation, and direct interventions. In 2010, €43 billion will go, for example, to farmers in the European Union as direct income support. Farmers are eligible to these subsidies if they maintain their land in good agricultural and environmental condition, and comply with standards on public, plant and animal health, and animal welfare. Payment eligibility is the responsibility of the EU member states, for which each country needs an Integrated Administration and Control System, including a land Parcel Identification System (LPIS). The LPIS provides a unique identifier to each land parcel and its owner (the claimant), and is used to register applications for the subsidies and payments made. The development, update, and revision of the LPIS, which can be based on existing maps and documents from national land registers, is increasingly based on high resolution aerial photography and satellite imagery.

The use of EO in beach nourishment [32] is another example of remote sensing supporting the implementation of a direct financial intervention in the Netherlands [33]. Beach nourishment aims to restore the coastal protection offered by dunes and beaches weakened by shore erosion. Airborne laser altimetry is used to estimate the volume of sand required for beach nourishment by measuring the 
elevation of the dry parts of the beach; sonar is used for the underwater parts (Figure 4). This information is used to direct the companies contracted to nourish the beaches. Maintenance of coastal defence lines is a task of the central government (Ministry of Public Works), which uses a financial instrument to achieve its policy objective of improving coastal defence through beach nourishment. EO contributes to the efficacy and efficiency of achieving this policy, while assessing the volume of sand required.

Figure 4. Laser altimetry and sonar bathymetry used to measure beach elevation is used to estimate the volume of sand required to restore the coastal defence function of the beach (Courtesy D. van der Vlag, [33]).

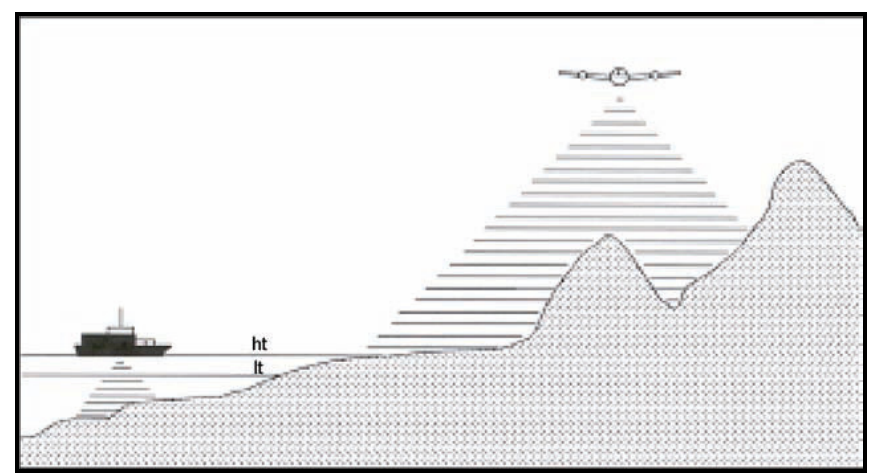

Financial instruments also trigger the use of EO in the context of the Kyoto protocol, which requires reliable and transparent approaches for the estimation of carbon stocks and for the emission and removal of greenhouse gases from agriculture, forestry, and other land uses. The use of remote sensing has been advised to support the accounting of carbon credits, while assessing carbon stocks, carbon sequestration by vegetation [34,35], and the implementation of payments under the REDD+ (Reduction of Emissions from Deforestation and Forest Degradation) policy [36], which is currently under discussion.

\subsection{Disaster Risk Management}

Given the spatial, and frequently dynamic nature of all aspects of disaster risk (hazard, elements at risk, vulnerability, disaster risk, and disasters) and also of the commonly considered phases of the disaster cycle (mitigation, preparedness, early warning, response, and recovery), remote sensing is superbly suited to study and monitor disaster risk [37]. This, however, does not happen in a policy context that is always equally well established. Hazard and risk assessment are increasingly part of urban and regional planning policies, with spatial analysis, frequently supported by remote sensing data, serving to assess the probability of loss in a given area and for given time periods due to environmental hazards. In particular, policies designed to limit losses due to floods or wildfires are employed and aided by RS data [38,39]. Remote sensing has also become a critical tool for hazard types that are more difficult to assess, such as seismic hazards. By providing detailed information on the hazard's spatio-temporal characteristics, remote sensing not only supports implementation of policies aimed at loss reduction, such as requirements for adequate construction standards or no-build zones, but also for such policies to be defined in detail in the first place. 
While RS-based response to natural disasters is naturally ad hoc and case-driven, a policy framework for international support to disaster response based in satellite imagery has been developed. The International Charter "Space and Major Disasters", established in 1999, provides for rapid image acquisition and damage map production, and is widely seen as a successful example of international cooperation. However, while the Charter operates within the framework of Space Law, i.e., the legally binding Outer Space Treaty, and the United Nations' non-binding Remote Sensing Principles, it employs a best-effort approach with no legal binding, and no liability is assumed for the resulting mapping products [40].

\section{Policy Control}

\subsection{Policy Enforcement}

RS information is increasingly used in policy control, with the purpose of enforcing policy and promoting compliance to regulations, as well as to detecting and avoiding fraud. Examples showing the potential of remote sensing in verifying compliance to regulations on an ad hoc basis include control on illegal drugs production[41], land use impacts on protected areas [42], illegal logging [43], and urban sprawl in China [44]. More recently, dedicated operational applications have been developed to control illegal marine fisheries [45] and marine oil spills [46,47].

\subsection{Fraud}

Earth observation is used in environmental policy control in agriculture [48]. While the EU, as explained in Section 4.4, subsidizes farmers, its member states are obliged to check and report compliance to regulations under the EU Common Agricultural Policy (CAP). The EU supports individual member states in implementing information systems that combine remote sensing and land parcel based information for the purpose of cross checking whether received subsidies comply with EU regulations. Pedersen [49] gives a detailed description of the use of remote sensing in crop subsidy control in Denmark. While initially developed to detect subsidy fraud, the CAP system has recently been expanded to also include compliance with environmental directives. Remote sensing is also used to detect fraud related to the Federal Crop Insurance Program set up by the US Department of Agriculture, which supports farmers in overcoming drought risks [50].

\subsection{Compliance to International Treaties}

It has been recognized since the mid 1990s [51] that EO has the potential to verify compliance toward international treaties [52-54], and increasingly, EO is used by governments in implementing their commitments to these treaties, while controlling and demonstrating their compliance. Remote sensing is also increasingly used by treaties to verify compliance of contracting and non-contracting parties, such as, for example, the treaty to restrict the proliferation of nuclear weapons [55]. Remotely sensed evidence of non-compliance has been used to mobilize signatories of this treaty to increase political pressure for the enforced compliance of non-compliant states.

More recently, interest has increased in the application of EO to enforce compliance with international environmental treaties, such as, for example, the Ramsar convention [56]. The application 
of remote sensing to enforce compliance with international environmental treaties, although technically feasible, is not straightforward because these treaties typically lack a framework to enforce compliance. Although RS alone cannot enforce compliance, since countries are sovereign to decide whether to react, RS can be used as evidence in the case of non-compliance and in the dissemination of remote sensing information that reveals lack of enforcement. This may increase pressure on non-compliant parties to improve performance.

\subsection{Legal Aspects and Potential of Remote Sensing}

The use of RS imagery as a source of information to support non-compliance or fraud ultimately requires admission of the remotely sensed information as evidence in court [57]. RS data's admissibility as evidence depends, amongst others factors, on the possibility of accurately detecting fraud and non-compliance in the imagery. The advent of sub-meter resolution satellite imagery greatly increased the potential of EO in policy control, as this allows for the accurate detection of indicators that are either not, or only poorly, discernable with lower resolution imagery. Purdy [57] further discusses the acceptance of EO as a source of evidence and privacy issues as barriers to the use of satellite imagery in policy control.

The potential of EO in policy control has long been recognized [58] and Purdy [57] concludes that the greatest use of remote sensing may lie in the field of compliance and enforcement. It is also our impression that remote sensing has a much wider potential for application in policy control than has been realized so far. It remains difficult, however, to assess the actual use and potential of this market. While the use of satellite imagery has been prescribed as one of the ways to demonstrate compliance in case of EU agricultural policy, and the ESA developed RS techniques which could be employed by individual member states, it remains unclear to what extent remote sensing is being used for this purpose in actual practice. One reason for this could be the aforementioned lack of publications reporting on the actual use of earth observation, but it might also be a deliberate choice, as detailed explanations on how RS is used in policy control might trigger control avoidance strategies.

The market of EO in control would appear very attractive when imagining that this would require continuous monitoring. It is questionable, however, whether continuous monitoring would be required; the rumour that remote sensing is used might affect behaviour such that incidental control would suffice. No studies so far have been undertaken to assess how detection of fraud and non-compliance by EO influences behaviour, and we suggest it would be interesting to study this.

\section{Policy Evaluation}

There are two main categories of purpose for policy evaluation [59]. The first is to evaluate whether the intended goals for which a policy has been designed have been achieved. Related to this is the desire to learn whether the chosen policy instruments have been effective. The second is to evaluate the impacts of policy other than those it was designed (i.e., to assess possible unintended consequences). 


\subsection{Evaluating Achievement of Intended Impacts}

Tian et al. [60] used a time series of remote sensing imagery to confirm whether objectives for which a policy was designed were met, while confirming that the rate of urban growth, which was high in the period between 1986 and 1999, slowed down after government policy aimed to reduce expansion of the urban area into agricultural lands. These authors attribute the reported reduction in urban expansion to this change in policy.

In case of the Montreal protocol, it is more difficult, based on remotely sensed information alone, to attribute the observed stabilization of the ozone hole (Figure 5) to policy. It is the congruence of the remote sensing record and predictions made by process based atmospheric chemistry models, which strengthen the confidence that the stabilization is attributable to the ban on CFCs.

Figure 5. Stabilization of the springtime size (millions $\mathrm{km}^{2} 7$ September-13 October) of the Antarctic ozone hole since the middle of the 1990s [16].

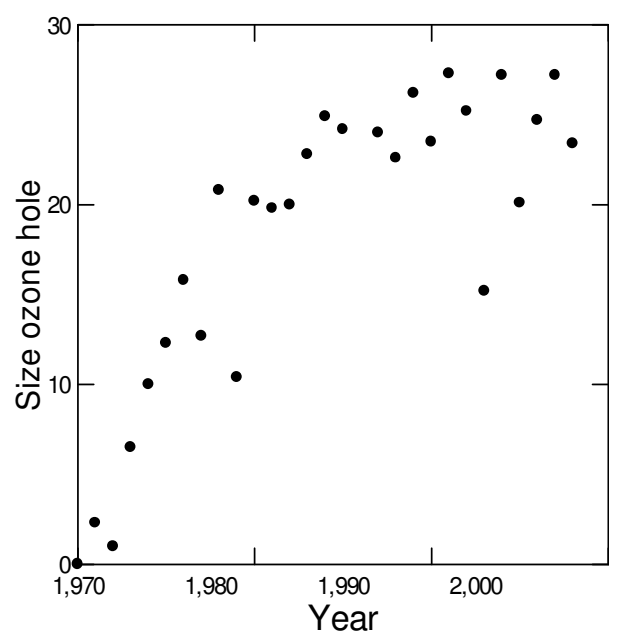

The above example indicates that, while remote sensing allows for the detection of whether a system changes as expected, it remains more difficult to attribute such change to policy impact. Impact analysis assumes causation, the inference of which is complicated when using observational data, as is frequently the case in remote sensing studies, rather than data from designed experiments. This problem is common in ex post impact evaluation, and a number of analytical techniques have been proposed to overcome this [61], such as, for example, BACI (before-after, control-impact) designs [62]. The ability to attribute an outcome to the policy designed to achieve this outcome has clear societal benefits; it allows the reconsideration and adaptation of the policy concerned and we suggest that remote sensing, notwithstanding the above caveat, holds far more potential for ex post policy impact assessment than so far explored.

\subsection{Evaluating Unintentional Side Effects}

Remote sensing also holds the potential for evaluating the unintended side effects that are inherent to any policy. The dredging in Poyang Lake, for example, started in 2001 as a result of a policy to ban sand mining on the Yangtze River, following frequent accidents between commercial navigation and 
dredging vessels [63]. This policy, which solved the problem of navigation on the Yangtze River, resulted in increased water turbidity in northern Poyang Lake (Figure 3) as an unintended side effect.

Another example is the use of remote sensing to assess the land use efficiency and environmental side effects of two rural development pathways in northern Argentina [64]. The observation that government sponsored colonization programs were leading to the expansion of low productivity agriculture at the expense of forest, while increased yields per hectare in areas with large market driven soybean farming resulted in enhanced agricultural output on a reduced area, led Grau et al. [64] to conclude that large scale market driven rural development better balanced nature conservation and food production by having a significantly higher agricultural land use efficiency and, therefore, allowing for more land to be retained for nature conservation.

Many policy driven interventions influence the space where these interventions are implemented. The above examples indicate that remote sensing has the potential to evaluate such localized policy side effects, and as such, to provide for the information required to reconsider and eventually adapt policy.

\section{A Review of Policy in the Remote Sensing Literature}

While reviewing the above, it was noticed that most of the examples were published outside the peer reviewed literature. This raised our interest in the question as to whether, and to what extent, peer reviewed literature contributes to the debate on the policy support of remote sensing. We therefore executed a literature search for papers on "remote sensing OR earth observation AND policy" published from 1991 onwards [65], which retrieved 302 peer reviewed papers. The number of remote sensing papers that refer to policy increased from 1991 to 2007 by $15.3 \%$ annually, which is significantly higher (two sample t-test, $\mathrm{t}=19.1$, d.f. $=16, \mathrm{P}<0.001$ ) than the $8.8 \%$ growth rate of the remote sensing literature as a whole (Figure 6).

Figure 6. Trends in the total number of remote sensing papers $(\Delta)$ and number of RS papers referring to policy (o) published between 1991 and 2007 as retrieved from ISI records.

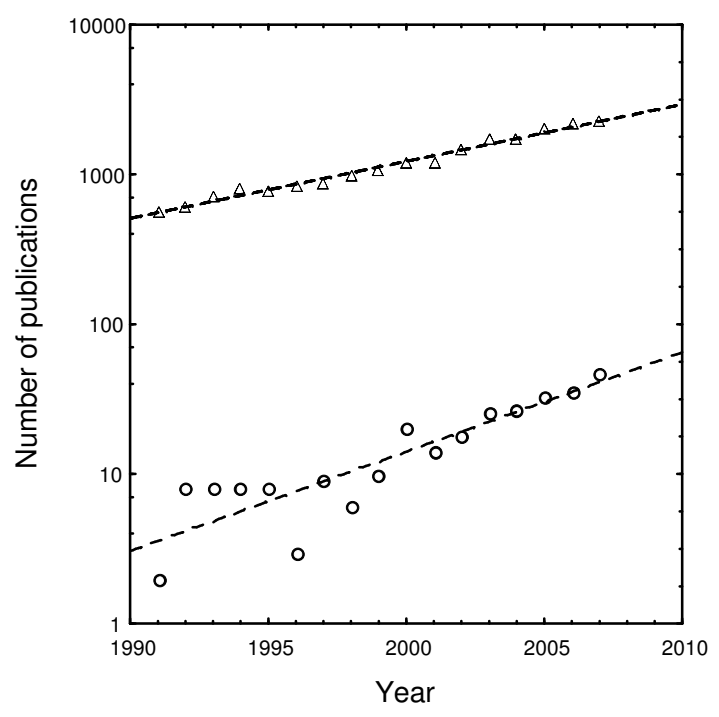


The trend displayed in Figure 6 suggests an increasing interest of the remote sensing community in the relation between EO and policy. However, although all papers associated policy to remote sensing, not a single of these 302 papers described the actual support of EO to a specific policy. Instead, the majority of papers demonstrate or claim a potential of EO to support environmental policy. Other papers relate EO to policy while considering policies to support the EO industry financially [66], policies for the acquisition, access, and distribution of remote sensing data [4], or policies as an explanatory variable in empirical research.

\section{Discussion}

Our review revealed that the various phases of environmental policy require up-to-date and synoptic spatial information, at various spatial scales, on the state of the environment and the extent and magnitude of environmental and policy impacts over larger areas. Earth observation is ideally suited for this, as a large number of variables relevant to environmental policy, but by far not all, can be detected remotely. Moreover, remote sensing permits repeated and consistent assessment and monitoring of the environment; it allows independent control and its quality can be assessed. As such, it is a tool with some very desirable characteristics for supporting environmental policy.

Why, given this potential, is remote sensing not used more widely? It has been stated frequently that remote sensing may address user requirements more cost effectively than traditional environmental information acquisition methods. Having the potential to be more cost effective, however, does not automatically lead to utilization of remote sensing. It makes a difference whether the technology is introduced in an existing or a new market; cost of market development might prohibit the opening of new markets, while competition with vested interest might frustrate the introduction of remote sensing in markets served by more traditional data capture methods. In these cases, one might consider [67] suggestions to compare the costs and value of the information provided by remote sensing to other techniques.

Apart from cost effectiveness, one also has to consider characteristics which determine the user's appreciation of the value of the information, such as its accuracy, reliability, consistency, and timeliness of delivery. Increasing standards for accuracy, reliability, and consistency are important fields of remote sensing research, as they increase the competitiveness of remote sensing products relative to traditional earth and atmosphere based measurements. The importance of timeliness of delivery in post hazard assessment has been stressed in drought [68], flood, and other hazard impact assessments [69]. Timeliness of information delivery is also crucial in radar detection of illegal fishing boats, as well as illegal oil spills, to allow the navy to intercept suspect vessels [45].

The examples given in this review confirm the picture that environmental policy creates a demand for remote sensing. This has implications for the possibility of financing remote sensing applications, as the opportunities for funding differ throughout the policy cycle. The best opportunities to acquire financial support are within the policy implementation phase, because of the significant budgets typically available for policy implementation. Likewise, it should be possible to mobilize budgets for policy control from within operational interventions, as good governance requires a more proactive attitude towards policy enforcement and control of fraud. Most examples of the use of EO for policy evaluation, rather than being intentionally integrated into the implementation of running policy, appear 
to have been developed by interested researchers. Remote sensing, with the caveats given, has great potential to evaluate policy, but budgets for policy evaluation are typically more difficult to acquire as this evaluation tends to be "forgotten" when implementing policy. Evaluation is considered an integral part of any policy cycle, and it is here that the effectiveness of governance could be assessed. Financing from within existing policies is not straightforward for the problem identification function of $\mathrm{EO}$, as it precedes the implementation of policy and the release of the related budgets.

Considering the use of EO in a policy context made us realize how policy dependent EO is. There is a potential for policy independent environmental EO applications, for example, in precision agriculture [70] and insurances [71-73]. Apart from this, there are certainly possibilities for commercialization within the context of environmental policies, particularly where budgets are available from within operational policy interventions. From a societal perspective, however, there is a need for those activities, which are more difficult to link to budgets within running policies, such as the timely recognition of problems and the critical evaluation of policy outcomes. We suggest that generous public funding should remain available to support those functions of EO which cannot be covered from within operational environmental policy interventions.

In this review, we argue that the societal support for environmental remote sensing applications relies strongly on the question of whether remote sensing addresses policy relevant issues. This is because policies largely determine the demand for EO products. The major societal benefit EO could make to environmental policy is to improve a policy's effectiveness and efficiency. The review has shown that remote sensing may contribute to this while supporting the need to address environmental problems, to implement interventions to address these issues, to control whether policies are executed, and to evaluate whether such policies influence the system as intended. It is interesting to note that initially (in the 1970s and 1980s), remote sensing was used almost exclusively to identify problems and contribute to the implementation of policy. More recently, interest also developed in applying remote sensing in policy control and evaluation. It is information on these later parts of the policy cycle which allows remote sensing to assess whether policy is effective. This assessment of the effectiveness of a policy forms a crucial part of good governance, and we suggest that remote sensing holds the potential to contribute to governance while filling this information gap.

Initially, those typically urging for policy development, the public and NGOs, had limited access to remotely sensed information, since the technical expertise required to process satellite imagery was restricted to state agencies. The proliferation of freely available satellite imagery and image processing capacity has resulted in increased capacity outside government. This trend is further stimulated by the availability of web-based information systems, such as Google Earth and Google Maps, which provide users easy access to satellite imagery. Nowadays, researchers, as well as NGOs, apply RS to mobilize support for cases requiring policy development, a process which has been called satellite imagery activism [74]. The media play an important role here, while distributing remote sensing studies to wide audiences. This enhances the effectiveness of the remote sensing information, because wider awareness increases the demand for policy development.

Our literature review was focused on the specific search within those papers that dealt with earth observation and environmental policy. If we turn to the wider policy literature, we find stark divisions regarding the role of technical information (which includes remote sensing) in policy making. Policy scholars are divided between those who express confidence in the capacity of bureaucratic circles to 
acquire and use high quality technical information by integrating the talents of large numbers of technical specialists and those who "have frequently concluded that such information is often -and, perhaps, primarily -used to legitimate decisions reached on other grounds, that is, prior to an adequate analysis of the magnitude of the problem and the probable consequences of alternative policies" [6]. For example, in spatial policy making, some assume geo-information to be an objective and scientifically accurate resource, with the role of providing spatially relevant information to rational decision making. Critics argue that geo-information and spatial policy do not have an unproblematic, linear, and direct relationship [75]. In choosing between policy options, political arguments are more salient than scientific arguments. "The question is not whether planning will reflect politics, but whose politics it will reflect. What values and whose values will planners seek to implement?" [76]. However, things are gradually changing. Remote sensing is now increasingly appearing in scholarly articles by political scientists-notably the 2009 Nobel Prize winner Elinor Ostrom [77], who argues that the study of complex ecosystems requires the conduct of "long-term research programs that use research methods that focus at different temporal and spatial scales, such as time series remote images, repeated on-the-ground social-ecological surveys of local stakeholders and their forests, and experimental laboratory studies."

Most papers reviewed in our literature search presented remote sensing techniques and claimed their potential to support policy. Fewer papers linked to an actual policy, while even fewer related to a specific part of the policy cycle. We are not aware of any peer reviewed papers analyzing the contribution of remote sensing to specific policy. The limited interest in the contribution of EO to environmental policy fits into a picture phrased by Quevauviller [78], who noticed while writing about $\mathrm{R} \& \mathrm{D}$ research funded by the European Union, that 'research to support any environmental policy should be feeding the policy-making process directly', but that 'in many instances this is still far from being the case'. Currently, other media, such as the Internet and professional non-peer reviewed literature, disseminate experiences with respect to how EO applications support environmental policy. Continued support for remote sensing depends however, on how well the remote sensing community articulates and demonstrates the benefits of remotely sensed information to the public sake.

The GIS and remote sensing academic community have only recently started to conduct cross-disciplinary research. Carton's [79] research in deliberative spatial policy-making practices in the Netherlands shows that the use of geo-information can resolve or deepen the conflict between policy actors. Moody [80] argues that only part of the potential of GIS in policy formulation has been reached, and it can be expected that more of this potential will be reached as GIS applications are used more frequently. We suggest that the academic remote sensing community could deepen our insight in the interaction between the EO and its societal context, and propose to consider bridging this gap, while more explicitly stimulating scientific debate and research on this interaction.

This paper reviewed the use, potential, and limitations of remote sensing in support of environmental policy. We highlighted how the contribution and limitations of remote sensing differ between the various parts of a policy cycle in the anticipation that this insight will enable policy-makers to appreciate the policy supporting potential of earth observation and the remote sensing community to address, more effectively, the opportunities offered by environmental policy. 


\section{Acknowledgements}

We wish to express our gratitude to the former vice-minister of Nature and Environment of Mongolia, B. Enkhmandakh and Eric M.A. Smaling (ITC, Enschede), for their stimulating support and critically reviewing this paper respectively.

\section{References}

1. Gore, A. An Inconvenient Truth. The Planetary Emergency of Global Warming and What We Can Do About It; Rodale Press: New York, NY, USA, 2006.

2. Johnston, S.; Cordes, J. Public good or commercial opportunity? Case studies in remote sensing commercialization. Space Policy 2003, 19, 23-31.

3. Christian, E. Planning for the Global Earth Observation System of Systems (GEOSS). Space Policy 2005, 21, 105-109.

4. Lautenbacher, C.C. The Global Earth Observation System of Systems: Science serving society. Space Policy 2006, 22, 8-11.

5. Esty, D.C. Environmental protection in the information age. In Public Law and Legal Theory; Research Paper Series 58; Yale Law School: New Haven, CT, USA, 2004.

6. Sabatier, P. The acquisition and utilization of technical information by administrative agencies. Admin. Sci. Quart. 1978, 23, 396-417.

7. Stone, D. Policy Paradox: The Art of Political Decision Making; revised ed; W. W. Norton \& Company: New York, NY, USA, 2002.

8. Sabatier, P.A. Theories of the Policy Process; Westview Press: Boulder, CO, USA, 2007.

9. Parsons, W. Public Policy: An Introduction to the Theory and Practice of Policy Analysis; Edward Elgar Publishing Ltd: Cheltenham, UK and Northampton, MA, USA, 2005.

10. Revenga, C. Developing indicators of ecosystem condition using geographic information systems and remote sensing. Reg. Environ. Chang. 2005, 5, 205-214.

11. Christie, M. Data collection and the ozone hole: Too much of a good thing? In Proceedings of the International Commission on History of Meteorology; ICHM: Mexico City, Mexico, 2004; Volume 1, pp. 99-105.

12. Molina, M.J.; Rowland, F.S. Stratospheric sink for chlorofluoromethanes: Chlorine atomc-atalysed destruction of ozone. Nature 1974, 249, 810-812.

13. Stolarski, R.S.; Krueger, A.J.; Schoeberl, M.R.; McPeters, R.D.; Newman, P.A.; Alpert, J.C. Nimbus 7 satellite measurements of the springtime Antarctic ozone decrease. Nature 1986, 322, 808-811.

14. Farman, J.C.; Gardiner, B.G.; Shanklin, J.D. Large losses of total ozone in Antarctica reveal seasonal C10x/NOx interaction. Nature 1985, 315, 207-210.

15. Velders, G.J.M.; Andersen, S.O.; Daniel, J.S.; Fahey, D.W.; McFarland, M. The importance of the Montreal Protocol in protecting climate. Proc. Nat. Acad. Sci. USA 2007, 104, 4814-4819.

16. NASA. Ozone Watch. Available online: http://ozonewatch.gsfc.nasa.gov/monthly/ monthly_1982-10.html (accessed on 22 June 2010). 
17. Wu, G.; de Leeuw, J.; Skidmore, A.K.; Prins, H.H.T.; Liu, Y. Concurrent monitoring of vessels and water turbidity enhances the strength of evidence in remotely sensed dredging impact assessment. Water Res. 2007, 41, 3271-3280.

18. Fok, M.; Pang, T. Finless porpoises in Wuhan, China. Newsletter of the Department of Ecology and Biodiversity, The University of Hong Kong 2006, 34, 18-20.

19. Zhong, Y.; Chen, S. Impact of dredging on fish in Poyang Lake. Jiangxi Fish. Sci. Tech. 2005, 1, 15-18.

20. Marklund, L.G.; Schoene, D. Global Forest Resources Assessment 2005. Global Assessment of Growing Stock, Biomass and Carbon Stock; Working paper 106/E; FAO: Rome, Italy, 2006; p. 55.

21. Nghiem, S.V.; Rigor, I.G.; Perovich, D.K.; Clemente-Colón, P.; Weatherly, J.W.; Neumann, G. Rapid reduction of Arctic perennial sea ice. Geophys. Res. Lett. 2007, 34, L19504.

22. Chen, J.L.; Wilson, C.R.; Tapley, B.D. Satellite gravity measurements confirm accelerated melting of Greenland Ice Sheet. Science 2006, 313, 1958-1960.

23. IPCC. Climate Change, the Scientific Basis. Contribution of Working Group 1 to the Third Assessment Report of the Intergovernmental Panel on Climate Change; Cambridge University Press: Cambridge, UK, 2001; p. 881.

24. IPCC. Climate Change 2007: the Physical Basis. Contribution of Working Group I; Fourth Assessment Report of the Intergovernmental Panel on Climate Change; Cambridge University Press: Cambridge, UK, 2007.

25. GCOS. The Second Report on the Adequacy of the Global Observing Systems for Climate in Support of the UNFCCC; WMO: Geneva, Switzerland, 2003.

26. Jordan, A.; Wurzel, R.K.; Zito, W.A. The rise of 'new' policy instruments in comparative perspective: Has governance eclipsed government? Polit. Stud. 2005, 53, 477-496.

27. ESA. Oil and gas producer switches to EO solutions. Success Stories, Earth Observation Market Development 9 January 2003. Available online: http://www.eomd.esa.int/stories/ story126.asp (accessed on 20 May 2010).

28. Bocco, G.; Mendoza, M.; Velázquez, A. Remote sensing and GIS-based regional geomorphological mapping-A tool for land use planning in developing countries. Geomorphology 2001, 39, 211-219.

29. IAIA. Priciples of Environmental Impact Assessment Best Practice; International Association for Impact Assessment: Fargo, ND, USA, 1996; p. 4.

30. Rodriguez-Bachiller, A.; Glasson, J. Expert Systems and Geographical Information Systems for Impact Assessment; Taylor and Francis: London, UK, 2004; p. 400.

31. Khanna, P.V.; Kondawar, K. Application of remote-sensing techniques for environmental impact assessment. Curr. Sci. 1991, 61, 252-256.

32. Hamm, L.; Capobianco, M.; Dette, H.H.; Lechuga, A.; Spanhoff, R.; Stive, M.J.F. A summary of European experience with shore nourishment. Coast. Eng. 2002, 47, 237-264.

33. Van der Vlag, D.E. Modeling and Visualizing Dynamic Landscape Objects and Their Qualities. Ph.D. Thesis, Wageningen University: Wageningen, The Netherlands, 2006; p. 181.

34. Rosenqvist, A.C.; Milne, A.; Lucas, R.; Imhoff, M.; Dobson, C. A review of remote sensing technology in support of the Kyoto Protocol. Environ. Sci. Policy 2003, 6, 441-455. 
35. IPCC. Agriculture, Forestry and Other Land Use; 2006 IPCC Guidelines for National Greenhouse Gas Inventories; IPCC: Geneva, Switzerland, 2006; Volume 4.

36. Mollicone, D.; Achard, F.; Federici, S.; Eva, H.D.; Grassi, G.; Belward, A.; Raes, F.; Seufert, G.; Stibig, H.J.; Matteucci, G.; Schulze, E.D. An incentive mechanism for reducing emissions from conversion of intact and non-intact forests. Climate Change 2007, 83, 477-493.

37. Kerle, N.; Heuel, S.; Pfeifer, N. Real-time data collection and information generation using airborne sensors. In Geospatial Information Technology for Emergency Response; Zlatanova, S., Li, J., Eds.; Taylor \& Francis/Balkema: Leiden, The Netherlands, 2008; p. 43-74.

38. Busenberg, G.J. Adaptive policy design for the management of wildfire hazards. Amer. Behav. Sci. 2004, 48, 314-326.

39. Fairbrother, A.; Turnley, J.G. Predicting risks of uncharacteristic wildfires: Application of the risk assessment process. Forest Ecol. Manage. 2005, 211, 28-35.

40. Ito, A. Issues in the implementation of the international charter on space and major disasters. Space Policy 2005, 21, 141-149.

41. Messina, J.P.; Delamater, P.L. Defoliation and the war on drugs in Putumayo, Colombia. Int. J. Remote Sens. 2006, 27, 121-128.

42. Ellis, E.A.; Porter-Bolland, L. Is community-based forest management more effective than protected areas? A comparison of land use/land cover change in two neighboring study areas of the Central Yucatan Peninsula, Mexico. Forest Ecol. Manage. 2008, 256, 1971-1983.

43. Fuller, D.O. Tropical forest monitoring and remote sensing: A new era of transparency in forest governance? Sing. J. Trop. Geogr. 2006, 27, 15-29.

44. Yeh, A.G.-O.; Li, X. Measurement and monitoring of urban sprawl in a rapidly growing region using entropy. Photogramm. Eng. Remote Sensing 2001, 67, 83-90.

45. Kourti, N.; Shepherd, I.; Greidanus, H.; Alvarez, M.; Aresu, E.; Bauna, T.; Chesworth, J.; Lemoine, G.; Schwartz, G. Integrating remote sensing in fisheries control. Fisheries Manag. Ecol. 2005, 12, 295-307.

46. Brekke, C.; Solberg, A.H.S. Oil spill detection by satellite remote sensing. Remote Sens. Environ. 2005, 95, 1-13.

47. Ferraro, G.; Bernardini, A.; David, M.; Meyer-Roux, S.; Muellenhoff, O.; Perkovic, M.; Tarchi, D.; Topouzelis, K. Towards an operational use of space imagery for oil pollution monitoring in the Mediterranean basin: A demonstration in the Adriatic Sea. Mar. Pollut. Bull. 2007, 54, 403-422.

48. Carleer, A.P.; Wolff, E.VHR image region-based classification potential in the framework of the control with remote sensing of the European CAP. In Remote Sensing for Agriculture, Ecosystems, and Hydrology VII; Owe, M., D’Urso, G., Eds.; SPIE: Brugge, Belgium, 2005.

49. Pedersen, B.F. The European way of controlling area based subsidies. In Proceedings of IEEE 2001 International Geoscience and Remote Sensing Symposium IGARSS'01, Sydney, NSW, Australia, 2001; pp. 1639-1641.

50. Rocchio, L. Fighting crop insurance fraud with Landsat. Photogramm. Eng. Remote Sensing 2006, 27, 725-727.

51. Gupta, V. Remote sensing and photogrammetry in treaty verification: present challenges and prospects for the future. The Photogrammetric Record 1994, 14, 729-745. 
52. Arino, O.; Fernandez-Prieto, D.; Volden, E. Healing the earth, earth observation supporting international environmental conventions. ESA Bull. 2006, 128, 53-60.

53. Kuriyama, I. Supporting multilateral environmental agreement with satellite earth observation. Space Policy 2005, 21, 151-160.

54. Peter, N. The use of remote sensing to support the application of multilateral environmental agreements. Space Policy 2004, 20, 189-195.

55. Niemeyer, I.; Nussbaum, S. Change detection: The potential for nuclear safeguards. In Verifying Treaty Compliance; Springer: Berlin/Heidelberg, Germany, 2006; pp. 335-348.

56. Rosenqvist, A.C.; Finlayson, M.; Lowry, J.; Taylor, D. The potential of long-wavelength satellite-borne radar to support implementation of the Ramsar Wetlands Convention. Aqua. Conserv. Mar. Freshwater Ecosyst. 2007, 17, 229-244.

57. Purdy, R. Satellites: A new era for environmental compliance? J. Eur. Environ. Plan. Law 2006, 3, 406-413.

58. Macauley, M.; Brennan, T. Enforcing Environmental Regulation: Implications of Remote Sensing Technology; Resources for the Future: Washington, DC, USA, 1998; p. 49.

59. Boothroyd, P. Policy assessment. In Environmental and Social Impact Assessment; Vanclay, F., Bronstein, D.A., Eds.; John Wiley \& Sons: Chichester, UK, 1996; pp. 83-126.

60. Tian, G.J.; Yang, Z.F.; Xie, Y. Detecting spatiotemporal dynamic landscape patterns using remote sensing and the lacunarity index: A case study of Haikou City, China. Environ. Plan. B-Plan. Design 2007, 34, 556-569.

61. Mohr, L.B. Impact Analysis for Program Evaluation, 2nd ed.; SAGE: Thousand Oaks, CA, USA, 1995.

62. Smith, E.P. BACI design. In Encyclopedia of Environmetrics; El-Shaarawi, A.H., Piegorsch, W.W., Eds.; John Wiley: Chichester, UK, 2002; pp. 141-148.

63. China bans illegal sand mining on Yangtze River. People's Daily 13 December 2000.

64. Grau, H.R.; Gasparri, N.I.; Aide, T.M. Balancing food production and nature conservation in the Neotropical dry forests of northern Argentina. Glob. Change Biol. 2008, 14, 985-997.

65. ISI. Web of Science. Search for "remote sensing" OR "earth observation" AND "policy" performed on the 3rd of July 2008.

66. Harris, R. Earth observation data policy and Europe. Space Policy 2001, 17, 55-60.

67. Macauley, M.K. The value of information: Measuring the contribution of space-derived earth science data to resource management. Space Policy 2006, 22, 274-282.

68. Hutchinson, C.F. Uses of satellite data for famine early warning in sub-Saharan Africa. Int. J. Remote Sens. 1991, 12, 1405-1421.

69. Tralli, D.M.; Blom, R.G.; Zlotnicki, V.; Donnellan, A.; Evans, D.L. Satellite remote sensing of earthquake, volcano, flood, landslide and coastal inundation hazards. ISPRS J. Photogramm. Remote Sens. 2005, 59, 185-198.

70. Moran, M.S.; Inoue, Y.; Barnes, E.M. Opportunities and limitations for image-based remote sensing in precision crop management. Remote Sens. Environ. 1997, 61, 319-346. 
71. Apan, A.; Chandler, O.; Young, F.R.; Maraseni, T.N. Opportunities and limitations of remote sensing for crop loss (hail damage) assessment in the insurance industry. In Proceedings of 2005 Spatial Sciences Institute Biennial Conference: Spatial Intelligence, Innovation and Praxis, Melbourne, Australia, September 2005.

72. Atwood, J.; Watts, T.; Price, K.; Kastens, J. The big picture-Satellite remote sensing applications in rangeland assessment and crop insurance. In Agricultural Outlook Forum 2005; US Department of Agriculture: Washington, DC, USA, 2005.

73. Kalluri, S.; Gilruth, P.; Bergman, R. The potential of remote sensing data for decision makers at the state, local and tribal level: experiences from NASA's Synergy program. Environ. Sci. Policy 2003, 6, 487-500.

74. Baker, J.C.; Williamson, R.A. Satellite imagery activism: Sharpening the focus on tropical deforestation. Sing. J. Trop. Geogr. 2006, 27, 4-14.

75. Faloudi, A.; Waterhout, B. The Making of the European Spatial Development Perspective: No Masterplan; RTPI Library Series; Routledge: New York, NY, USA, 2002.

76. Dühr, S. The Visual Language of Spatial Planning: Exploring Cartographic Representations for Spatial Planning in Europe; RTPI Library Series; Routledge: New York, NY, USA, 2007.

77. Ostrom, E.; Nagendra, H. Insights on linking forests, trees, and people from the air, on the ground, and in the laboratory. Proc. Nat. Acad. Sci. USA 2006, 103, 19224-19231.

78. Quevauviller, P. Science-policy interfacing in the context of the WFD implementation. J. Soils Sediments 2006, 6, 259-261.

79. Carton, L.J. Map Making and Map Use in a Multi-Actor Context: Spatial Visualizations and Frame Conflict in Regional Policy Making in the Netherlands. Ph.D. Thesis, Delft University of Technology, Delft, The Netherlands, 2007.

80. Moody, R. Has incrementalism murdered the hype? An assessment of the potential and actual use of geographical information systems in policy design, in ICTs, Citizens and Governance: After the Hype! In Innovation and the Public Sector; Meijer, A., Boersma, K., Wagenaar, P., Eds.; IOS Press: Amsterdam, The Netherlands, 2009; pp. 83-96.

(C) 2010 by the authors; licensee MDPI, Basel, Switzerland. This article is an Open Access article distributed under the terms and conditions of the Creative Commons Attribution license (http://creativecommons.org/licenses/by/3.0/). 